\title{
Comparison of the Effects of Remifentanil and Esmolol on Peroperative Hemodynamics and Postoperative Pain in Septum Deviation
}

\author{
Sevil Tufekci*, Zeynep Nur Orhon, Zeynep Collak and Fatma Nur Akgun \\ Department of Anesthesiology and Reanimation, Istanbul Medeniyet University \& Goztepe Training and Research Hospital, Turkey
}

Submission: April 23, 2019; Published: June 17, 2019

*Corresponding author: Sevil Tufekci, Istanbul Medeniyet University Medical Faculty, Department of Anesthesiology and Reanimation, Fahrettin Kerim Gokay Street, Goztepe, Kadikoy, Istanbul, Turkey

\begin{abstract}
Introduction: The aim of this study was to compare the effects of remifentanil and esmolol infusion used for controlled hypotension on hemodynamics and postoperative pain in elective septoplasty cases.

Materials and methods: Forty ASA I - II patients aged 18-55 years were included in the study. The patients were divided into two groups as R (remifentanil) and group E (esmolol). ECG, noninvasive blood pressure and peripheral oxygen saturation were monitored. None of the patients were premedicated. After anesthesia induction, in Group R $0.25 \mu \mathrm{g} / \mathrm{kg} / \mathrm{min}$ remifentanil infusion was started following $1 \mu \mathrm{g} / \mathrm{kg}$ loading dose of remifentanil. In Group E, $50 \mu \mathrm{g} / \mathrm{kg} / \mathrm{min}$ esmolol infusion was given after $500 \mu \mathrm{g} / \mathrm{kg} / \mathrm{min}$ loading dose. Doses were gradually increased until the targeted 65-75mmHg OAB was reached. Blood pressure, Heart Rate (HR) and oxygen saturation (Sp02) values were recorded during the operation and postoperatively. Modified Aldrete Scoring was used in the evaluation of recovery. Postoperative pain was evaluated using the visual analog scale (VAS). Side effects were recorded.
\end{abstract}

Results: There was no statistically significant difference between the groups in terms of their effects on heart rate, blood pressure, SpO2 values, Aldrete scores and the presence of postoperative nausea and vomiting. VAS values were significantly lower in group R than group E.

Conclusion: Esmolol is a good alternative to remifentanil in the management of hypotensive anesthesia. However, remifentanil was better in pain management.

Keywords: Controlled hypotension; Remifentanil; Esmolol

\section{Introduction}

The aim of ideal anesthesia is to provide surgical comfort and hemodynamic stability without damaging the physiology of the organism, and to achieve a balanced and safe recovery in a short time.

Hypotensive anesthesia is preferred in surgeries in narrow areas such as septoplasty. For this purpose, controlled hypotension is applied. Controlled hypotension is a method that aims to consciously and reversibly reduce the Mean Arterial Pressure (MAP) up to $50-65 \mathrm{mmHg}$. It was first introduced by Cushing in 1917 [1].

Controlled hypotension provides better surgical field of view reducing the amount of bleeding. Bleeding control is easier under controlled hypotension. Therefore the trauma to the tissues is minimized. Surgical procedure can be done in short time, better and easily. Although it is difficult to rate the blood loss, it is accepted that blood loss can be reduced by $50 \%$ with controlled hypotension. Remifentanil, which is frequently used for controlled hypotension, is a narcotic analgesic, one of the agents with short-acting, rapid onset and easily titrated. Recently, esmolol, a short-acting, cardio-selective beta-blocking agent that has a rapid effect, has also been used for this purpose. In our study, we compared the effects of esmololol, a cardioselective betablocker and remifentanil, an opioid analgesic on hemodynamics and postoperative pain, in a group of patients with controlled hypotension in elective septoplasty procedures.

\section{Material and Methods}

An institutional ethical committee approval and informed consent were obtained for this prospective study. A total of 40 ASA I - II patients aged 18-55 years were included in the study. For the standardization of the group, the patients have Mean Arterial Pressure (MAP) below $50 \mathrm{mmHg}$ and heart rate below 50 beats/ min, who has been used antihypertansive and anticoagulant drug who has coronary artery disease, morbid obese, pregnant and patients in lactation, who has drug abuse, liver and kidney 
disease and those with severe anemia were excluded from the study. The patients were randomly divided into two groups as R (Remifentanil) and Group E (Esmolol). Patients without premedication were taken to the operating room. ECG in standard D2 derivation, heart rate, non-invasive Systolic Arterial Pressure (SAP), Diastolic Arterial Pressure (DAP), Mean Arterial Pressure (MAP) and Peripheral Oxygen Saturation $\left(\mathrm{SpO}_{2}\right)$ were monitored. The values were used as follow-up parameters. Following a 3-minute preoxygenation with $100 \%$ oxygen, anesthesia induction was achieved with $5-7 \mathrm{mg} / \mathrm{kg}$ thiopental sodium (Pental sodium $1 \mathrm{~g}$, İ.E Ulagay), $1 \mu \mathrm{g} / \mathrm{kg}$ fentanyl (Fentanyl-citrate, Abbott, USA). Esmeron (Rocuronium, Organon, Netherlands) 0.5mg/ $\mathrm{kg}$ was given intravenously and endotracheal intubation was performed. Anesthesia was maintained with 4-6\% desflurane and $50 \% \mathrm{~N}_{2} \mathrm{O}-50 \% \mathrm{O}_{2}$. A standard dose of lidocaine (with adrenaline) infiltration was performed on the surgical site by the surgical team. Loading dose was given after intubation and all parameters were recorded. Then a remifentanil infusion at $0.25 \mu \mathrm{g} / \mathrm{kg}$ was started. The infusion rate was increased by $0.025 \mu \mathrm{g} / \mathrm{kg} / \mathrm{min}$ every 5 minutes to reach the targeted MAP (65-75mmHg). After esmolol (Brevibloc) $500 \mu \mathrm{g} / \mathrm{kg} / \mathrm{min}$ loading dose in Group E, $50 \mu \mathrm{g} / \mathrm{kg} / \mathrm{min}$ esmolol infusion was started, it was gradually increased and targeted MAP value was reached. During the initial surgical incision, and during the operation at $5,15,30,45 \mathrm{~min}$, and at every $15 \mathrm{~min}$, follow-up parameters were recorded. The heart rate $\leq 50$ beats/min was accepted as bradycardia and the infusion rate was decreased. Even if the MAP was allowed to decrease to
$60 \mathrm{mmHg}$, the infusion rate of the drug was halved if it lasts longer than 60 seconds. If there is no improvement in 5 minutes, the drug was discontinued. When the heart rate was 45 beats/min, $0.01 \mathrm{mg} / \mathrm{kg}$ atropine was administered intravenously. The dose was repeated when necessary. Changes in ECG were recorded. All hypotensive and anesthetic agents were discontinued during insertion of nasal tampons and metochlorpropamide $10 \mathrm{mg}$ was given intravenously. When spontaneous respiration started, the effect of the muscle relaxant was reversed using IV $0.06 \mathrm{mg} /$ $\mathrm{kg}$ neostigmine and $0.02 \mathrm{mg} / \mathrm{kg}$ atropine. Follow-up parameters of patients were recorded postoperatively. Postoperative pain scoring was performed using the Visual Anologue Scale (VAS) at $0,5,10$, and 30 minutes. Side effects such as nausea, vomiting, agitation, bradycardia, cough, tremors, reflex tachycardia and rebound hypertension were recorded. Patients were evaluated according to Modified Aldrete recovery score at 0,10 , and 30 minutes at the end of anesthesia. Patients who reached 9 and above were sent to their clinics.

\section{Statistical analysis}

For multiple comparisons of descriptive statistics (arithmetic mean and standard errors) and group averages, SPSS V17 packet program was used for Duncan test calculations, and MS Office Excell program was used for plotting graphs. Significance levels were shown as $\mathrm{P}<0.05$ for $\alpha=0.05$ and $\mathrm{P}<0.01$ for $\alpha=0.05$. $\mathrm{P}>0.05$ indicates that the differences were not statistically significant.

Results

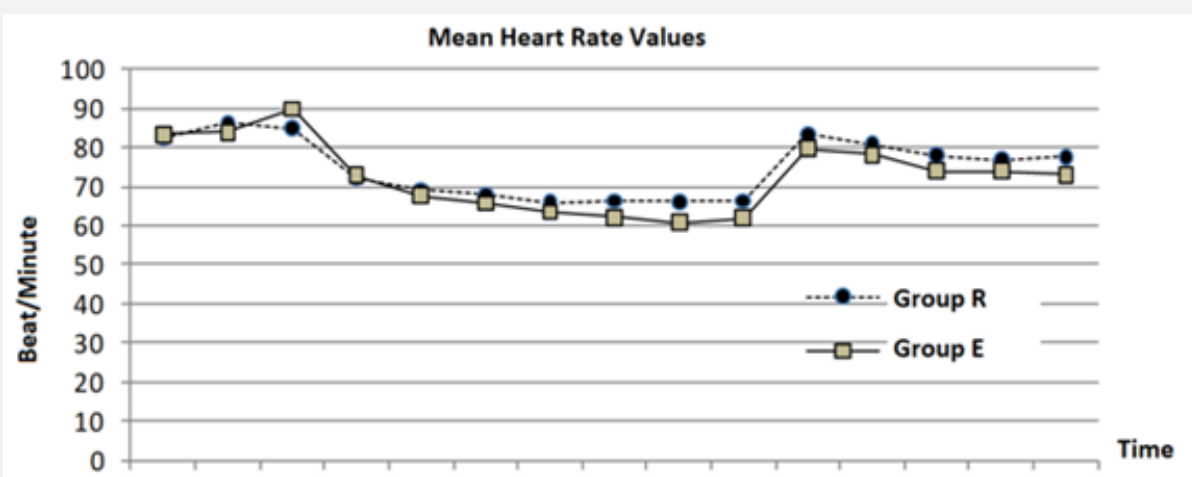

\begin{tabular}{|c|c|c|c|c|c|c|c|c|c|c|c|c|}
\hline 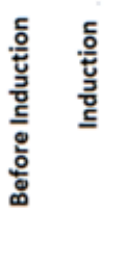 & 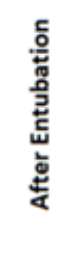 & 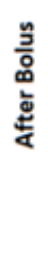 & 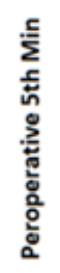 & 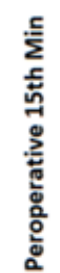 & 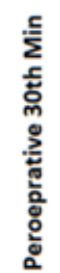 & 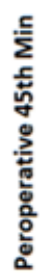 & 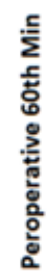 & 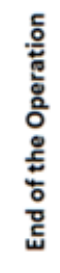 & 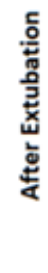 & 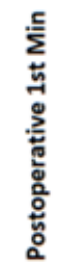 & 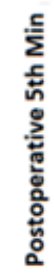 & 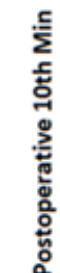 \\
\hline
\end{tabular}

Figure 1: Average Heart Rate Values Change in Time in R and E Groups.

The values obtained from the study were examined, it was determined that there was no statistically significant difference between the drug groups in terms of their effects on heart rate (Figure 1). Heart rate was higher and statistically significant at 45 and 60 minutes of operation and at postoperative 30 minute in
Group R compared to Group E $(\mathrm{P}<0.05)$. SAP, DAP and MAP values were not different after induction between groups. A significant decrease occured following the bolus dose, and continued at the same level until the end of operation. There was no statistically significant difference between $\mathrm{R}$ and $\mathrm{E}$ groups regards to SAP, 


\section{Journal of Anesthesia \& Intensive Care Medicine}

DAP and OAP values throughout the operation ( $\mathrm{p}>0.05$ ), (Figure $2-4)$. There was no statistically significant difference between the groups in terms of their effects on $\mathrm{SpO}_{2}$ (Figure 5). VAS values of Group R and Group E were compared, and found that it was low and statistically significant at all time periods except after extubation. The VAS values were measured as 2,390 in group $\mathrm{R}$ and 3,330 in group E (Figure 6). VAS value of Group $\mathrm{R}$ at the postoperative 1st, 5th, 10th and 30th minutes were lower than Group E and the difference was statistically significant $(\mathrm{p}<0.05)$. There was no statistically significant difference between the groups according to the presence of postoperative nausea and vomiting $(\mathrm{p}=0.231>0.05)$ (Table 1$)$, in atropine requirement $(p=0.337>0.05)$ (Table 2) and in Aldrete Scores (Table 3).

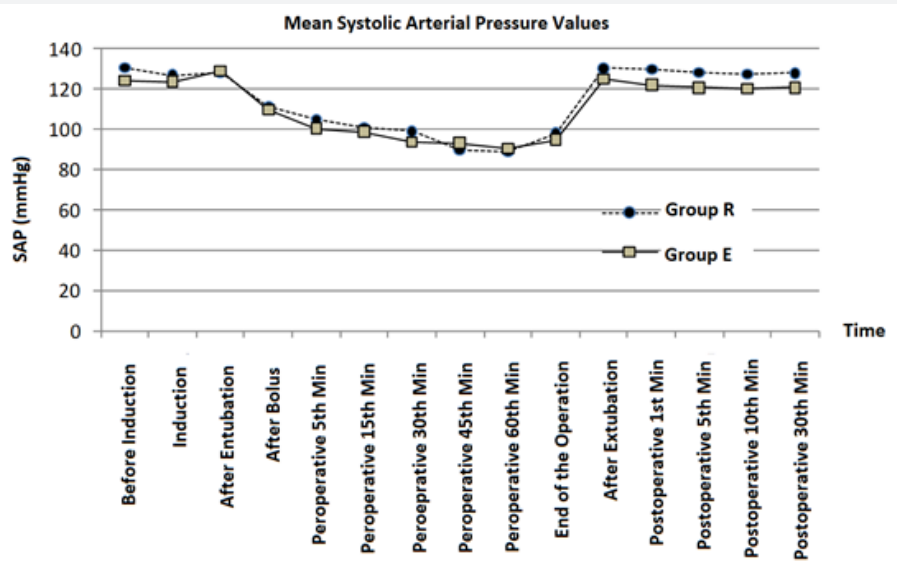

Figure 2: Variation of Systolic Arterial Pressure Values by Time in R and E Groups.

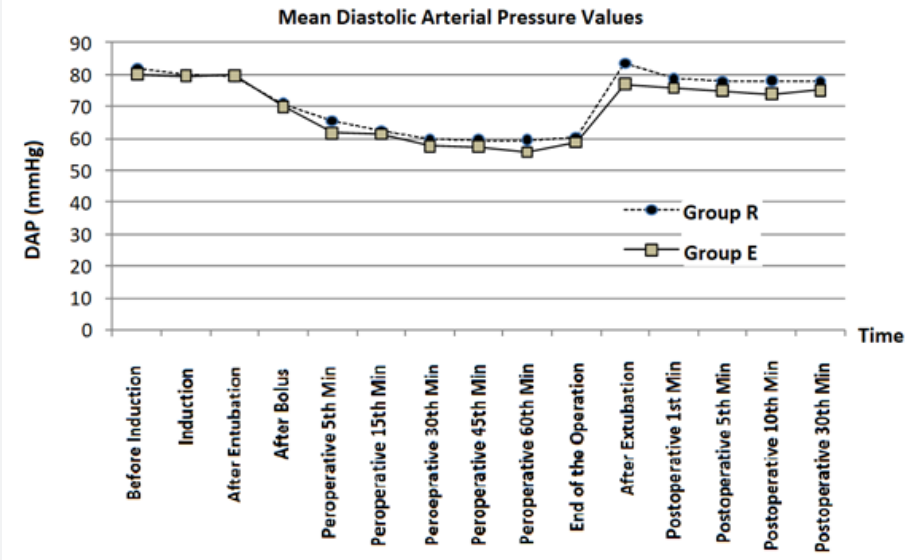

Figure 3: Variation of Diastolic Arterial Pressure Values by Time in R and E Groups.

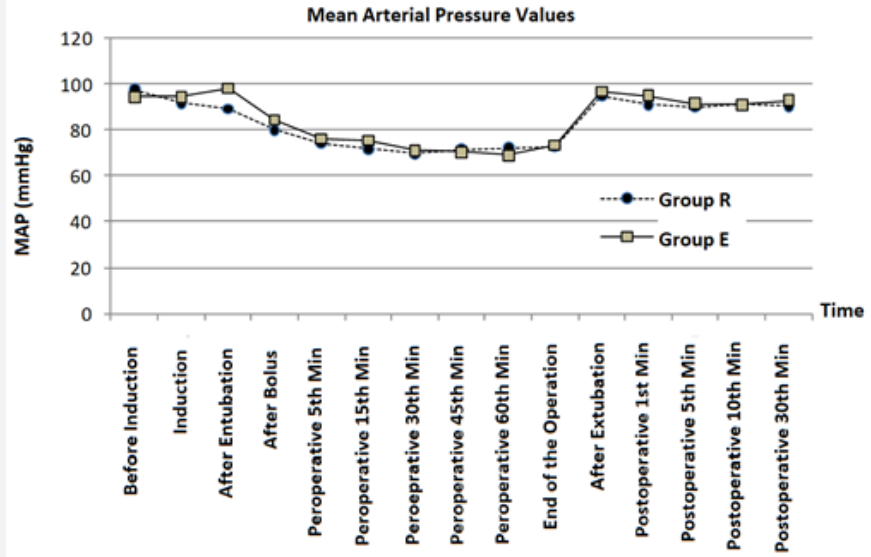

Figure 4: Variation of Mean Arterial Pressure Values by Time in R and E Groups. 


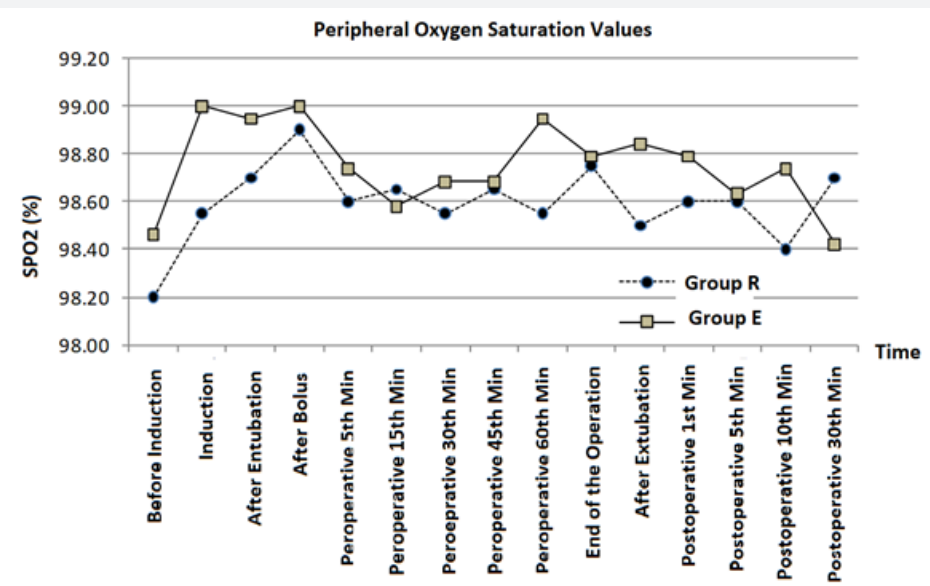

Figure 5: Change of Peripheral Oxygen Saturation Values in Time in R and E Groups.

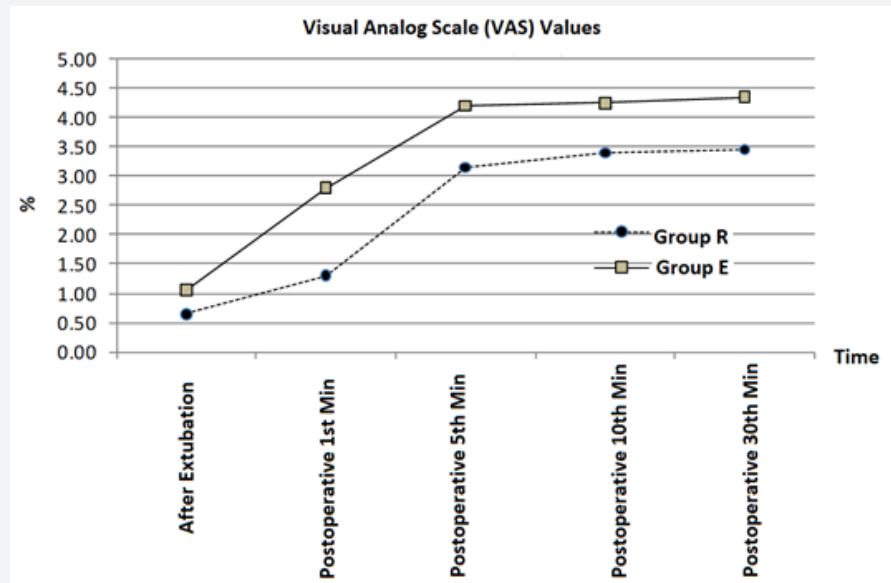

Figure 6: Change of VAS Values by Time in R and E Groups.

Table 1: Comparison of the groups according to the presence of postoperative nausea and vomiting.

\begin{tabular}{|c|c|c|c|c|c|c|}
\hline & & \multicolumn{2}{|c|}{ Group R } & \multicolumn{2}{|c|}{ Group E } & \multirow{2}{*}{ p } \\
\hline & & $\mathbf{n}$ & $\%$ & $\mathbf{n}$ & $\%$ & \\
\hline \multirow{2}{*}{ Nausea and Vomiting } & Present & 3 & 15 & 1 & 5 & \multirow{2}{*}{0.231} \\
\hline & Absent & 17 & 85 & 19 & 95 & \\
\hline
\end{tabular}

Table 2: Comparison of the groups according to atropine requirement.

\begin{tabular}{|c|c|c|c|c|c|c|}
\hline & & \multicolumn{2}{|c|}{ Group R } & \multicolumn{2}{|c|}{ Group E } & \multirow{2}{*}{ p } \\
\hline & & $\mathrm{n}$ & $\%$ & $\mathrm{n}$ & $\%$ & \\
\hline \multirow{2}{*}{ Atropine Requirement } & Present & 5 & 25 & 3 & 15 & \multirow{2}{*}{0.337} \\
\hline & Absent & 15 & 75 & 17 & 85 & \\
\hline
\end{tabular}

Table 3: Comparison of the groups according to Aldrete Scores.

\begin{tabular}{|c|c|c|c|}
\hline & Group R & Group E & P \\
\hline Aldrete 0 minutes & $8,70 \pm 0,163$ & $8,80 \pm 0,138$ & 0.192 \\
\hline Aldrete 5. minutes & $9,00 \pm 0,162$ & $9,00 \pm 0,145$ & 0.537 \\
\hline Aldrete 10 minutes & $9,85 \pm 0,082$ & $9,90 \pm 0,069$ & 0.351 \\
\hline Mean \pm SD & $9,183 \pm 0,102$ & $9,233 \pm 0,093$ & 0.339 \\
\hline
\end{tabular}

${ }^{*} p<0.05$ is significant.

\section{Discussion}

The aim of general anesthesia; to provide adequate depth hypnosis, analgesia and appropriate surgical environment. Controlled hypotension is one of the applications used to provide better surgical field of vision by reducing the amount of bleeding. Various methods and drugs can be used to create controlled hypotension. The main targets of the drug selection are safety of the drug, rapid onset and termination of the effect, non-toxicity, rapid elimination and minimal effect on the blood flow to the vital organs. Remifentanil is a short-acting, fast-acting, easily titrated opioid analgesic. The hypotensive side effect is used for controlled hypotension.

In controlled hypotension, sympatholiths are also frequently used. Esmolol is a short-acting, rapid onset cardioselective $\beta$-adrenergic receptor blocker. In addition its analgesic effect is an advantage to other sympatholiths. In our study, we compared the effects of the $\mu$-opioid receptor agonist remifentanil and esmolol on hemodynamics and postoperative pain in elective septoplasty interventions. Sang Jun et al. [2] divided patients into two groups, esmolol and remifentanil administered to one group, saline and remifentanil were given to the other group in laparoscopic 
appendectomy patients. Perioperative nausea and vomiting, pain score, antiemetic and analgesic requirement were evaluated.

Esmolol supplementation has been shown to increase the analgesic effect of remifentanil and decrease postoperative nausea and vomiting. In saline group postoperative nausea, vomiting, pain and mean arterial pressure values were significantly higher during intubation and extubation. It was observed that these patients needed more antiemetic and analgesic within the first 24 hours [2].

Shukkla et al. [3] investigated the effects of perioperative esmolol on anesthesia and on postoperative pain in 60 ASA 1-2 patients undergoing lower abdominal surgery. Esmolol was given 15 minutes before and 15 minutes after the induction [3]. In the esmolol group, hemodynamia was more stable, postoperative pain score was lower, the use of morphine with PCA was less ( $p<0.05$ ) when compared to the saline group. Gökçe et al. [4] divided the ASA 1 group 40 patients into two groups for controlled hypotension. One group received remifentanil-propofol combination and the other group received esmolol infusion in addition to remifentanilpropofol combination. The consumption of remifentanil was significantly lower in the esmolol group. It was reported that there was no difference between the groups in terms of recovery times [4].

Aydin et al used remifentanil and esmolol in 36 adult patients who underwent tympanoplasty for controlled hypotension. In the remifentanil group, the target was achieved much faster and the $\mathrm{HR}, \mathrm{OAB}$ values were lower than the esmolol group. In the Esmolol group, hemorrhage decreased in the first 20 minutes, but at first 60 minutes the bleeding scores were high. Remifentanil was accepted as a good, stable and reliable hypotensive agent in anesthesia [5]. Collard et al. [6] studied 90 patients who underwent laparoscopic cholecystectomy in three groups. In the control group fentanyl was given intermittently, in the second group esmolol infusion $5-15 \mathrm{mcg} / \mathrm{kg} / \mathrm{min}$ was given and in the third group remifentanil infusion $0.1-0.5 \mathrm{mcg} / \mathrm{kg} / \mathrm{min}$ was given. The amount of fentanyl given for postoperative analgesia was significantly lower in the esmolol group compared to the other two groups $(p<0.001)$. The frequency of nausea was significantly lower in the esmolol group $(\mathrm{p}<0.01)[6]$.

Chia et al. [7] administered $0.05 \mathrm{mg} / \mathrm{kg}$ esmolol infusion following $0.5 \mathrm{mg} / \mathrm{kg}$ esmolol bolus in ASA 1-2 group 97 patients undergoing hysterectomy prior to anesthesia induction, and the other group received normal saline at the same loading and infusion doses. In the esmolol group, inhalation anesthetic and fentanyl consumption decreased [7]. Degoute et al. [8] administered remifentanil $1 \mu \mathrm{g} / \mathrm{kg}$ to the first group of 40 ASA I children who had middle ear surgery, and sodium nitroprusside $0.25 \mu \mathrm{g} / \mathrm{kg} / \mathrm{min}$ and alfentanil $25 \mu \mathrm{g} / \mathrm{kg}$ were given to the second group at the induction of anesthesia for controlled hypotension. In the maintanence of anesthesia remifentanil infusion was administered $0.2-0.5 \mu \mathrm{g} / \mathrm{kg} /$ minutes in the first group, and the second group received $0.25 \mu \mathrm{g} / \mathrm{kg} /$ minutes sodium nitroprusside infusion and $0.5 \mu \mathrm{g} / \mathrm{kg} / \mathrm{min}$ alfentanil infusion. Middle ear blood flowmeasured with laser doppler and it has been concluded that the combination of remifentanil and sevoflurane provides better surgical field by reducing middle ear blood flow and no additional hypotensive agent was required [8]. Similarly, in our study, remifentanil and esmolol were used for controlled hypotension, it was provided in both groups, and no additional hypotensive agent was needed. In another study; esmolol, remifentanil and nitroprusside were compared to provide controlled hypotension in tympanoplasty by Degoute et al. [9]. The targeted $80 \mathrm{mmHg}$ pressure was achieved fastest with esmolol. In all three groups, the bleeding in the surgical area was found to decrease by $80 \%$ and no postoperative complication was observed. In the esmolol group, middle ear blood flow decreased more than remifentanil and sodium nitroprusside groups [9].

Coloma et al. [10] investigated the use of esmolol as an alternative to remifentanil in 53 patients who underwent laparoscopic tubal ligation. Esmolol and remifentanil infusions were found to be equivalent in maintaining hemodynamic stability [10]. Lim et al. [11] compared $500 \mu \mathrm{g} / \mathrm{kg} / \mathrm{min}$ esmolol bolus, and $100 \mu \mathrm{g} / \mathrm{kg} / \mathrm{min}$ esmolol infusion and $200 \mu \mathrm{g} / \mathrm{kg} / \mathrm{min}$ esmolol infusion and placebo in patients undergoing intracranial surgery. Similar results were obtained in intraoperative sleep depth, postoperative recovery, need for additional analgesic and home discharge time. Systolic blood pressure and heart rate increased after extubation in all three groups. In the placebo group, 92\% of patients had severe hypertension and tachycardia during and after extubation. It was concluded that hemodynamic response was more easily controlled with esmolol infusion and it was beneficial for patient safety and prophylactic esmolol infusion did not affect extubation time. There was no statistically significant difference between low-dose esmolol infusion and mid-dose esmolol infusion [11]. Watts et al. [12] conducted a meta-analysis in which investigated the effect of the peroperative percutaneous esmolol on postoperative early pain. It has been concluded that esmolol does not affect the time of awakening, decreases pain intensity, opioid consumption and postoperative nausea and vomiting [12]. Härkänen et al. performed a meta-analysis of 701 patients to evaluate the effects of beta adrenergic antagonists on peroperative pain. They stated that esmolol reduced the need for additional analgesic by $32-50 \%$, prolonged the first analgesic time and reduced the amount of pain and analgesic consumption [13]. Thiruvenkatarajan et al. [14] performed a meta-analysis comparing the effects of peroperative opioid and esmolol on nausea, vomiting, recovery time and analgesia. They stated that esmolol decreases postoperative nausea and vomiting, there is no difference between agents in terms of recovery time, early postoperative pain scores, opioid requirement and cumulative analgesic consumption [14]. The results of this study were compared with other results in the literature. The majority of studies have shown that esmolol provides better peroperative analgesia, lowers the incidence of nausea and vomiting, and 
suppresses hemodynamic response better. In this study, it was found that there was no difference between the remifentanil and esmolol groups in terms of the incidence of nausea and vomiting however, postoperative analgesia was better in remifentanil group. There was no difference between the two groups in terms of postoperative recovery. As a result, esmolol is a good and a safe alternative to remifentanil to provide controlled hypotension during anesthesia management. Remifentanil, however, provides better postoperative analgesia.

\section{References}

1. Esener ZK (2004) Controlled hypotension. Clinical Anesthesia $3^{\text {rd }}$ Edition. Logos Company, İstanbul, Turkey, pp. 496-502.

2. Sang Jung Lee, Jong Nam Lee (2010) The effect of perioperative esmolol infusion on the postoperative nause, votmiting and pain after laparoscopic appendectomy. Korean J Anesthesiol 59(3): 179-184.

3. Shukkla S, Krishna GMD, Pavan GMD (2010) Role Of Beta Blockade In Anaesthesia And Postoperative Pain Management After Major Lower Abdominal Surgery. The İnternet Journal of Anesthesiology 25(1).

4. Gökçe BM, Karabıyık L, Karadenizli Y (2009) Hypotensive anesthesia with esmolol. Assessment of hemodynamics, consumption of anesthetic drugs, and recovery. Saudi Med J 30(6): 771-777.

5. Aydın BG, Özlü O, Alacakır H, Aksoy M (2008) Controlled hypotension: remifentanil or esmolol during tympanoplasty. Mediterr J Otol 4: 2.

6. Collard V, Mistraletti G, Tagi A, Asenjio JF, Feldman LS ,Fried Gm, Carli F (2007) Anesth Analg 105 (5): 1255-1262.

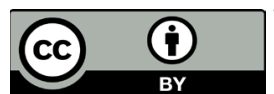

This work is licensed under Creative Commons Attribution 4.0 License

DOI: 10.19080/JAICM.2019.09.555755
7. Chia YY, Chan MH, Ko NH, Liu K (2004) Role of beta-blockade in anaesthesia and postoperative pain management after hysterectomy. Br J Anaesth 93(6): 799-805.

8. Degoute CS, Ray MJ, Gueugniaud Pierre Y, Dubreuil C (2003) Remifentanil induces consistent and sustained controlled hypotensision in children during middle ear surgery. Can J Anesth 50(3): 270-276.

9. Degoute CS, Ray MJ, Manchan M, Dubrevil C, Bonssillon C (2001) Remifentanyl and controlled hypotension; comparison with nitroprusside or esmolol during tympanoplasty. Can J Anaesth 48(1): 20-27.

10. Coloma M, Chiu JW, White PF, Armbruster SC (2001) The Use of Esmolol as an Alternative to Remifentanil During Desflurane Anesthesia for Fast-Track Outpatient Gynecologic Laparoscopic Surgery. Anesth Analg 92(2): 352-357.

11. Lim SH, Chin NM, Tai HY, Wong M (2000) Prophylactic Esmolol Infusion for the control of cardiovascular Responses to Extübation after Intracranial Surgery. Ann Acad Med 29(4): 447-451.

12. Watts R, Thiruvenkatarajan V, Calvert M, Newcombe G, Van Wijk RM (2017) The effect of perioperative esmolol on early postoperative pain: A systematic review and meta-analysis. J Anesthesiol Clin Pharmacol 33(1): 28-39.

13. Härkänen L, Halonen J, Selander T, Kokki H (2015) Beta-adrenergic antagonists during general anesthesia reduced postoperative pain: a systematic review and a meta-analysis of randomized controlled trials. J Anesth 29(6): 934-943.

14. Thiruvenkatarajan V, Watts R, Calvert M, Newcombe G, Van Wijk RM (2017) The effect of esmolol compared to opioids on postoperative nausea and vomiting, postanesthesia care unit discharge time, and analgesia in noncardiac surgery: A meta-analysis. J Anaesthesiol Clin Pharmacol 33(2): 172-180.

Your next submission with Juniper Publishers will reach you the below assets

- Quality Editorial service

- Swift Peer Review

- Reprints availability

- E-prints Service

- Manuscript Podcast for convenient understanding

- Global attainment for your research

- Manuscript accessibility in different formats

( Pdf, E-pub, Full Text, Audio)

- Unceasing customer service

Track the below URL for one-step submission

https://juniperpublishers.com/online-submission.php 